\title{
Braf and $e r b B 2$ mutations correlate with smoking status in lung cancer patients
}

\author{
HIDEFUMI SASAKI, MASAYUKI SHITARA, KEISUKE YOKOTA, KATSUHIRO OKUDA, \\ YU HIKOSAKA, SATORU MORIYAMA, MOTOKI YANO and YOSHITAKA FUJII \\ Department of Oncology, Immunology and Surgery, Nagoya City University \\ Graduate School of Medical Sciences, Nagoya 467-8601, Japan
}

Received August 23, 2011; Accepted January 16, 2012

DOI: $10.3892 /$ etm.2012.500

\begin{abstract}
The erbB pathway involves a family of tyrosine kinases and contributes to resistance or sensitivity to chemotherapy in many tumor types. Somatic mutations of the epidermal growth factor receptor $(E G F R)$ gene at the kinase domain have been found in lung cancer patients. These mutations are correlated with clinical response to targeted molecular therapy. Although Caucasian lung cancer patients have been shown to harbor Braf and $e r b B 2$ mutations, only a few reports exist concerning Braf and erbB2 mutations in Japanese lung cancer patients. We investigated the Braf and erbB2 mutation status in non-small cell lung cancer (NSCLC) patients by reverse transcription-polymerase chain reaction (RT-PCR) and direct sequencing. The study included 305 surgically removed lung cancer samples from the Nagoya City University Hospital, which were EGFR and Kras wild-type centric. Six Braf mutations were found in the adenocarcinoma cases. Among the adenocarcinoma cases, Braf mutations were more frequently noted in heavy smokers (Brinkman index $>400, \mathrm{p}=0.0476$ ). We also detected five $e r b B 2$ mutations all in the non-smokers. All of these mutations existed exclusively. The erbB2 gene mutations were predominantly found in non-smokers with adenocarcinomas. However, the completely exclusive mutation status could help us design individually tailored targeted molecular therapy for lung cancer.
\end{abstract}

\section{Introduction}

The epidermal growth factor receptor (EGFR) signaling pathway plays a crucial role in many carcinogenic processes, such as proliferation, angiogenesis, invasion and metastasis, and resistance to apoptosis $(1,2)$. Since deregulation of EGFR pathway genes has been observed frequently in various types

Correspondence to: Dr Hidefumi Sasaki, Department of Oncology, Immunology and Surgery, Nagoya City University Graduate School of Medical Sciences, 1 Kawasumi, Mizuho-cho, Mizuho-ku, Nagoya 467-8601, Japan

E-mail: hisasaki@med.nagoya-cu.ac.jp

Key words: Braf, epidermal growth factor receptor, lung cancer, mutations, $\operatorname{erbB2}$, adenocarcinoma of tumors, including non-small cell lung cancer (NSCLC), the development of targeted agents for lung cancer therapy has focused mainly on EGFR and its downstream networks (3), such as RAS/RAF/MAP kinase and PI3K/AKT, being the two major pathways $(3,4)$.

The pathway linking receptor tyrosine kinases to the Ras family to the Raf serine-threonine kinase to the MAP kinase cascade is critical for cell proliferation and is frequently activated in human cancers (5). MAP kinase, also known as extracellular signal-regulated protein kinase (ERK), is crucial for the transduction of growth signals from several key growth factors, such as EGF. ERK1 and ERK2, downstream effectors of the RAS-RAF-MEK-ERK-MAP kinase pathway, are constitutively active in many NSCLCs. Mutations of Braf were first reported in melanomas (over 60\%) and colorectal cancers. The V600E (previously reported as V599E) mutant form of Braf activates the RAF/MEK/ERK pathway in human melanoma cells in vitro, and transformation of a melanocyte cell line with mutant Braf was found to activate the MAP kinase pathway (6). Braf mutations have since been reported in $3 \%$ (7) and 1.6\% (8) of NSCLCs. Recently, additional studies have shown that somatic mutations of the Braf gene are found in approximately $2 \%$ of Caucasians $(9,10)$ and in $1.2 \%$ of East Asians (11).

The erbB family comprises four structurally related receptors: erbB1 (EGFR) to erbB4. On ligand stimulation, the receptor forms either homodimers or heterodimers, which activate their cytoplasmic domain. Several reports have shown that somatic mutations of the EGFR gene are found in $25-40 \%$ of Japanese NSCLC patients $(12,13)$, but only in $10 \%$ of NSCLC patients in the US $(14,15)$. EGFR mutations were predominantly found in female, non-smokers with adenocarcinomas (12-16). Actually, EGFR mutations in NSCLC have been correlated with clinical response to gefitinib therapy (17-19). In addition, it has been reported that $\operatorname{erbB} 2$ mutations at the kinase domain are present in $4 \%$ of European-derived NSCLC patients (20). Somatic erbB2 mutations are more frequent in never-smoker and adenocarcinoma histology (21). Although the $e r b B 2$ mutation was also investigated in Japanese NSCLC $(13,22)$, the Braf mutation frequency in Japanese NSCLC is not well known. We previously described a single Braf mutation case (23), however, in this study, we investigated the Braf mutation status in 305 surgically treated NSCLC cases. 


\section{Patients and methods}

Patients. This is a retrospective study. The study group included 305 lung cancer patients who had undergone surgery at the Department of Surgery II, Nagoya City University Medical School between 1997 and 2009. We also investigated the EGFR, erbB2 $(\mathrm{n}=249)$ and Kras mutation status for the same patient group. All tumor samples were immediately frozen and stored at $-80^{\circ} \mathrm{C}$ until assayed. The clinical and pathological characteristics of the 305 lung cancer patients are as follows: 180 cases at stage I, 51 at stage II and 74 at stage III-IV. The mean age was 66.1 years (range 39-88). Among the 305 lung cancer patients, 261 (85.6\%) were diagnosed as adenocarcinoma and $38(12.5 \%)$ were squamous cell carcinoma. The study was approved by the institutional ethics board and written

PCR assays for Brafand erbB2. Total RNA was extracted from lung cancer tissues and adjacent non-malignant lung tissues using the Isogen kit (Nippon Gene, Tokyo, Japan) according to the manufacturer's instructions. RNA concentration was determined by spectrophotometer and adjusted to a concentration of $200 \mathrm{ng} / \mathrm{ml}$. Approximately 20 cases were excluded since tumor cells were too few to sufficiently extract tumor RNA. RNA (1 $\mu \mathrm{g})$ was reverse-transcribed by Superscript II enzyme (Gibco BRL, Gaithersburg, MD, USA) with $0.5 \mu \mathrm{g}$ oligo(dT)12-16 (Amersham Pharmacia Biotech Inc. Piscataway, NJ, USA). The reaction mixture was incubated at $42^{\circ} \mathrm{C}$ for $50 \mathrm{~min}$ and then at $72^{\circ} \mathrm{C}$ for $15 \mathrm{~min}$. We then used $1 \mu 1$ of each DNA for PCR analyses. The PCR reactions were performed using the LA-Taq kit (Takara Bio Inc., Shiga, Japan) in a $25-\mu 1$ reaction volume. The primer sequences for the Braf gene for the kinase domain (exon 11-15) were as follows: the forward primer, 5-GACGGGACTCGAGTGATGAT-3 and the reverse primer, 5-CCACAAATGGATCCAGACA-3 (532 bp). The cycling conditions were as follows: initial denaturation at $94^{\circ} \mathrm{C}$ for $5 \mathrm{~min}$, followed by 35 cycles at $94^{\circ} \mathrm{C}$ for $40 \mathrm{sec}$, $60^{\circ} \mathrm{C}$ for $40 \mathrm{sec}$ and $72^{\circ} \mathrm{C}$ for $45 \mathrm{sec}$. The primer sequences for erbB2 gene for kinase domain (exon 19-22) were as follows: the forward primer, 5-CGCTTTTGGCACAGTCTACA-3 and the reverse primer, 5-GGGATCCCATCGTAAGGTTT-3 (594 bp). The cycling conditions were as follows: initial denaturation at $94^{\circ} \mathrm{C}$ for $5 \mathrm{~min}$, followed by 35 cycles at $94^{\circ} \mathrm{C}$ for $40 \mathrm{sec}, 60^{\circ} \mathrm{C}$ for $40 \mathrm{sec}$ and $72^{\circ} \mathrm{C}$ for $45 \mathrm{sec}$. The products were purified by the Qiagen PCR purification kit (Qiagen, Valencia, CA, USA). Amplified cDNAs were separated on $1 \%$ agarose gels, and the bands were visualized by ethidium bromide and photographed under ultraviolet transillumination. These samples were sequenced using the ABI Prism 3100 analyzer (Applied Biosystems Japan Ltd., Tokyo, Japan) and analyzed by BLAST and chromatograms by manual review from forward and reverse, both side. EGFR and Kras sequencing methods were previously submitted elsewhere $(12,13,16,24)$.

\section{Results}

Braf gene mutation status in Japanese lung cancer patients. Of the 305 patients, 93 had EGFR mutations within the kinase domain, including 45 exon 19 deletions, 41 L858R, 5 exon 20 insertion, 3 G719S and 2 L861Q. Twenty-two had

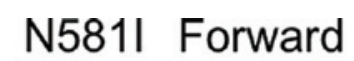

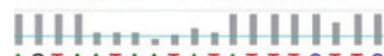

AGTAATAATATATTTCTTC

380

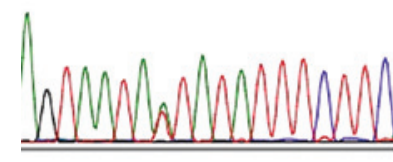

V600E Forward

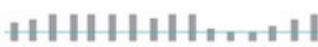

GT CTAGCTACAGTGAA

440

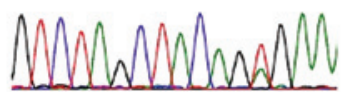

Reverse

HHMH,H|H||H| IATATATTAT TACTCT T

90

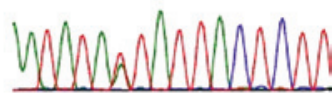

Reverse

H. $\underset{30}{T \text { T CAC T G TA GC T }}$

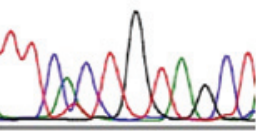

Figure 1. Braf mutations in lung cancer patients. One mutation consisted of N581I (1742 adenine to thymine; asparagine to isoleucine) (upper) and five were V600E (1799 thymine to adenine; valine to glutamic acid) (lower). Reverse sequence reading was also confirmed (right).

\section{5-776insYVMA; Forward}
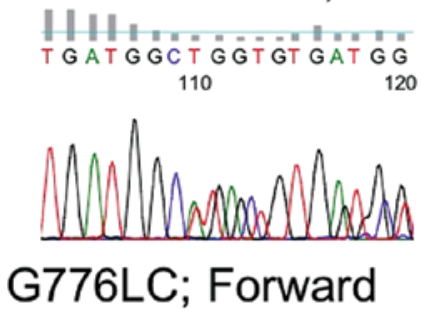

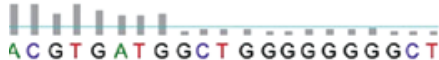

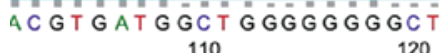

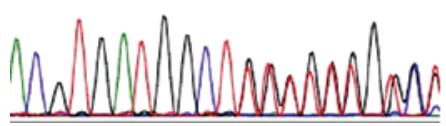

Reverse

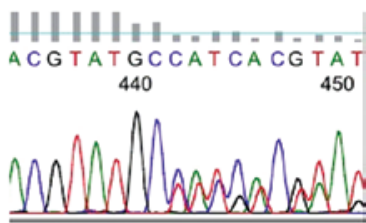

Reverse

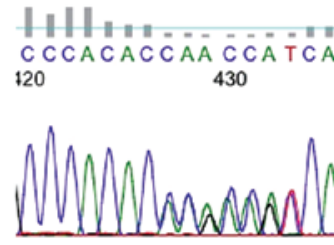

Figure 2. erbB2 mutations in lung cancer patients. Four cases consisted of 12 amino acid insertion mutation (2324-2325 ins ATACGTGATGGC), located in exon 20 at the kinase domain (775-776 ins YVMA) (upper). Reverse sequence for the $\operatorname{erbB2}$ gene was also confirmed (right) One had an amino acid insertion mutation (2326 G to TTGT), located in exon 20 at the kinase domain (776 glycine to leucine plus cysteine) (lower). Reverse sequence reading was also confirmed (right).

Kras mutations at codon 12 or 13 . Braf mutation was found in $6(1.96 \%)$ of the 305 NSCLC patients. Reverse sequence reading was also confirmed (Fig. 1). Five consisted of V600E (1799 thymine to adenine; valine to glutamic acid) and one was N581I (1742 adenine to thymine; asparagine to isoleucine). Four were male and 2 were female. Five were smokers and 1 was a never smoker. All were adenocarcinoma cases. Within the total cohort, there was no significant difference in the Braf mutation rate according to gender $(\mathrm{p}=0.8234)$, age $(\mathrm{p}=0.5050)$, pathological stage $(\mathrm{p}=0.7004)$ or smoking status (never smoker vs. smoker; $\mathrm{p}=0.6195$ ). However, in the adenocarcinoma cases, heavy-smoker group (Brinkman index $>400$ ) had a significantly higher Braf mutation rate than in the light-smoker or never-smoker group $(\mathrm{p}<0.05)$. There was no significant difference in the Braf mutation rate according to gender $(p=0.6449)$, age $(p=0.4665)$ and 
Table I. Clinicopathological data of the 261 lung adenocarcinoma patients.

\begin{tabular}{|c|c|c|c|}
\hline \multirow[b]{2}{*}{ Factors } & \multicolumn{2}{|c|}{ Braf gene status } & \multirow[b]{2}{*}{ p-value } \\
\hline & Mutant patients $(n=6)$ & Wild-type patients $(\mathrm{n}=255)$ & \\
\hline Mean age (years; $65.8 \pm 9.0$ ) & $69.0 \pm 8.7$ & $65.7 \pm 9.0$ & 0.4665 \\
\hline Stage & & & 0.7704 \\
\hline I & $4(2.5 \%)$ & $155(97.5 \%)$ & \\
\hline II-IV & $2(2.0 \%)$ & $100(98.0 \%)$ & \\
\hline Lymph node metastasis & & & 0.8182 \\
\hline NO & $4(2.2 \%)$ & $181(97.8 \%)$ & \\
\hline $\mathrm{N}+$ & $2(2.6 \%)$ & $74(97.4 \%)$ & \\
\hline Smoking status & & & 0.0476 \\
\hline $\mathrm{BI} \leq 400$ & $1(0.7 \%)$ & $146(99.3 \%)$ & \\
\hline $\mathrm{BI}>400$ & $5(4.4 \%)$ & $109(95.3 \%)$ & \\
\hline EGFR mutation & & & 0.0630 \\
\hline Mutation & $0 \quad(0 \%)$ & $94(100 \%)$ & \\
\hline Wild-type & $6(3.6 \%)$ & $161(96.7 \%)$ & \\
\hline Kras mutation & & & 0.4521 \\
\hline Mutation & $0 \quad(0 \%)$ & $22(100 \%)$ & \\
\hline Wild-type & $6(2.5 \%)$ & $233(97.5 \%)$ & \\
\hline Age (years) & & & 0.5054 \\
\hline$\leq 65$ & $2(1.6 \%)$ & $120(98.4 \%)$ & \\
\hline$>65$ & $4(2.9 \%)$ & $135(97.1 \%)$ & \\
\hline Gender & & & 0.6449 \\
\hline Male & $4(2.7 \%)$ & $109(97.3 \%)$ & \\
\hline Female & $2(1.8 \%)$ & $146(98.2 \%)$ & \\
\hline
\end{tabular}

Table II. Clinicopathological data of 248 NSCLC patients.

\begin{tabular}{|c|c|c|c|}
\hline \multirow[b]{2}{*}{ Factors } & \multicolumn{2}{|c|}{$\operatorname{erbB} 2$ gene status } & \multirow[b]{2}{*}{ p-value } \\
\hline & Mutant patients $(\mathrm{n}=5)$ & Wild-type patients $(n=243)$ & \\
\hline Mean age (years; $65.7 \pm 8.7$ ) & $68.0 \pm 5.0$ & $65.7 \pm 8.8$ & 0.5142 \\
\hline Stage & & & 0.3863 \\
\hline $\mathrm{I}$ & $2(1.4 \%)$ & $144(98.6 \%)$ & \\
\hline II-IV & $3(2.9 \%)$ & $99(97.1 \%)$ & \\
\hline Lymph node metastasis & & & 0.7083 \\
\hline N0 & $3(1.8 \%)$ & $165(98.2 \%)$ & \\
\hline $\mathrm{N}+$ & $2(2.5 \%)$ & $78(97.5 \%)$ & \\
\hline Smoking status & & & 0.0052 \\
\hline Never smoker & $5(5.1 \%)$ & $93(94.9 \%)$ & \\
\hline Smoker & $0 \quad(0 \%)$ & $150(100 \%)$ & \\
\hline EGFR mutation & & & 0.1828 \\
\hline Mutation & $0 \quad(0 \%)$ & $64(100 \%)$ & \\
\hline Wild-type & $5(2.7 \%)$ & $179(97.3 \%)$ & \\
\hline Pathology & & & 0.3846 \\
\hline Adenocarcinoma & $5 \quad(2.3 \%)$ & $211(97.7 \%)$ & \\
\hline Non-adenocarcinoma & $0 \quad(0 \%)$ & $32(100 \%)$ & \\
\hline Age (years) & & & 0.7046 \\
\hline$\leq 65$ & $2(1.7 \%)$ & $118(98.3 \%)$ & \\
\hline$>65$ & $3(2.3 \%)$ & $125(97.7 \%)$ & \\
\hline Gender & & & 0.2471 \\
\hline Male & $2(1.3 \%)$ & $158(98.7 \%)$ & \\
\hline Female & $3(3.4 \%)$ & $85(96.6 \%)$ & \\
\hline
\end{tabular}


pathological stage $(\mathrm{p}=0.7704)$ among the adenocarcinoma cases (Table I).

erbB2 gene mutation status in Japanese lung cancer patients. We also sequenced the kinase domain of erbB2 for 248 NSCLC patients. Among the 248 patients, 5 (2\%) had erbB2 mutations. All mutations were at exon 20. Three were female. All were non-smokers. Four had a 12 amino acid insertion mutation (2324-2325 ins ATACGTGATGGC), located in exon 20 at the kinase domain (775-776 ins YVMA). One had an amino acid insertion mutation (2326 G to TTGT) located in the exon 20 at kinase domain (776 glycine to leucine plus cysteine). Reverse sequence for the erbB2 gene was also confirmed. Never smokers had a significantly higher $\operatorname{erbB} 2$ mutation rate than the smokers $(\mathrm{p}=0.0052)$. There was no significant difference in the erbB2 mutation rate according to gender $(\mathrm{p}=0.2471)$, age $(\mathrm{p}=0.5142)$ and pathological stage $(\mathrm{p}=0.3863)$ (Table II).

Within these NSCLCs, all four gene (EGFR, erbB2, Kras and $B r a f$ ) mutations existed exclusively. All patients with Braf or $e r b B 2$ mutations were alive at this point and we did not perform survival analysis (data not shown).

\section{Discussion}

In the present study, we found six Braf mutations in 305 Japanese NSCLC cases. The Braf mutation was exclusively found without $E G F R$ or $e r b B 2$ mutations. Braf mutations were predominantly found in heavy smokers among the adenocarcinoma cases. This population was also thought to have a higher incidence of Kras gene mutations $(10,24)$. On the other hand, in our analysis, $e r b B 2$ gene mutations were predominantly found in non-smokers with adenocarcinomas.

The v-raf murine sarcoma viral oncogene homolog B1 (Braf) encodes a serine/threonine kinase that acts in the MAP kinase pathway, through both receptor tyrosine kinases and G-protein coupled receptors (5). Mutations in Braf were first reported in melanomas and colorectal cancers, but have since been reported in a variety of solid tumors $(6,7)$, including stage I lung adenocarcinomas (7). Activating Braf mutations, especially common mutant $\mathrm{V} 600 \mathrm{E}$, induce constitutive activation of the signal transduction pathway, providing a potent promitogenic force that drives malignant transformation (6). The Braf V600E mutant showed greatly increased activity in the Raf/MEK/Erk pathway both in vitro and in vivo $(6,25)$. An inducible transgenic mouse model of Braf V600E developed by Ji et al (26) demonstrated that mutant Braf was sufficient for the development of lung adenocarcinomas. Since the incidence of Braf mutations is highest in melanomas, the bulk of the clinical trials to date have focused on this disease, targeting either BRAF itself or MEK $1 / 2$, the latter of which is associated with growth-dependency in Braf mutant cell lines $(27,28)$. The most promising of specific agents has been PLX4032, which was associated with an $80 \%$ response rate in the extension phase of a recent multicenter phase I study that included 32 patients with advanced stage melanoma with Braf mutations (29).

Mutations in the erbB2 gene were found in approximately $2 \%$ of primary NSCLCs, predominantly in never smoker-like $E G F R$ mutations (12-16). It has been shown that the common erbB2 mutation, A775 ins YVMA, led to oncogenic transformation in a cellular assay (30). The mutations target residues that are highly conserved in the erbB family, and are homologous to the exon 20 insertion mutations of EGFR. Murine cells transformed with the mutant were relatively resistant to the reversible EGFR inhibitor, resembling the resistant phenotype found in cells carrying the homologous mutations in exon 20 of $\operatorname{EGFR}(31,32)$. However, the mutant cells exhibited high sensitivity to the irreversible dual-specificity EGFR/ERBB2 kinase inhibitor HKI-272 (30).

In our analysis, Braf or erbB2 mutations were only found in the adenocarcinomas, but not in the squamous cell carcinoma cases. It was also suggested that Braf mutations in Japanese NSCLC patients are not common and have an even lower frequency than that in US patients $(6,7)$, or in in vitro analysis from lung cancer cell lines (11\%) (5). Our data showed that mutations of the Braf or erbB2 gene as a mechanism of tumorigenesis are unlikely to be associated with many cases of Japanese NSCLCs. Despite the promise of anti-BRAF therapy or irreversible erbB inhibitors, our findings indicate that a small percentage of Japanese NSCLC patients actually harbor the Braf or $e r b B 2$ mutation and, in turn, a few patients with these tumors may likely benefit from these anticancer agents. However, completely exclusive EGFR, erbB2 and Braf mutation status would help us to choose individualized molecular targeting therapy for NSCLC. Further studies are required to confirm the mechanisms of Braf and erbB2 mutations involved in the sensitivity or resistance of targeted therapy for lung cancer.

\section{Acknowledgements}

This study was supported by Grants-in-Aid for Scientific Research, Japan Society for the Promotion of Science (JSPS) (nos. 23659674, 21390394, 21591820) and a grant for cancer research from the Program for Developing the Supporting System for Upgrading Education and Research (2009) from the Ministry of Education, Culture, Sports, Science and Technology of Japan. The authors would like to thank Mrs. Akiha Kuramoto and Miki Mochizuki for their excellent technical assistance.

\section{References}

1. Yarden Y and Sliwkowski MX: Untangling the ErbB signaling network. Nat Rev Mol Cell Biol 2: 127-137, 2001.

2. Rowinsky EK: The erbB family: targets for therapeutic development against cancer and therapeutic strategies using monoclonal antibodies and tyrosine kinase inhibitors. Annu Rev Med 55: 433-457, 2004.

3. Wieduwilt MJ and Moasser MM: The epidermal growth factor receptor family: biology driving targeted therapeutics. Cell Mol Life Sci 65: 1566-1584, 2008

4. Laurent-Puig P, Lievre A and Blons H: Mutations and response to epidermal growth factor receptor inhibitors. Clin Cancer Res 15: 1133-1139, 2009.

5. Peyssonnaux C and Eychene A: The Raf/MEK/ERK pathway: new concepts of activation. Biol Cell 93: 53-62, 2001.

6. Davies H, Bignell GR, Cox C, et al: Mutations of the BRAF gene in human cancer. Nature 417: 949-954, 2002.

7. Brose MS, Voipe P, Feldman M, et al: BRAF and RAS mutations in human lung cancer and melanoma. Cancer Res 62: 6997-7000, 2002.

8. Naoki K, Chen T-H, Richards WG, Sugarbaker DJ and Meyerson M: Missense mutations of the BRAF gene in human lung adenocarcinoma. Cancer Res 62: 7001-7003, 2002.

9. Hoque MO, Brait M, Rosenbaum E, et al: Genetic and epigenetic analysis of erbB signaling pathway genes in lung cancer. J Thorac Oncol 5: 1887-1893, 2010. 
10. Paik PK, Arcila ME, Fara M, et al: Clinical characteristics of patients with lung adenocarcinomas harboring Braf mutations. J Clin Oncol 29: 2046-2051, 2011.

11. Lee YS, Kim MJ, Jin G, et al: Somatic mutations in epidermal growth factor receptor signaling pathway genes in non-small cel lung cancers. J Thorac Oncol 5: 1734-1740, 2010.

12. Paez JG, Janne PA, Lee JC, et al: EGFR mutations in lung cancer: correlation with clinical response to gefitinib therapy. Science 304: 1497-1500, 2004.

13. Sasaki H, Shimizu S, Endo K, et al: EGFR and erbB2 mutation status in Japanese lung cancer patients. Int J Cancer 118: 180-184, 2006.

14. Lynch TJ, Bell DW, Sordella R, et al: Activating mutations in the epidermal growth factor receptor underlying responsiveness of non-small-cell lung cancer to gefitinib. New Eng J Med 350: 2129-2139, 2004.

15. Pao W, Miller V,Zakowski M, et al: EGF receptor gene mutations are common in lung cancers from 'never smokers' and are associated with sensitivity of tumors to gefitinib and elrotinib. Proc Natl Acad Sci USA 101: 13306-13311, 2004.

16. Sasaki H, Endo H, Konishi A, et al: EGFR mutation status in Japanese lung cancer patients: genotyping analysis using LightCycler. Clin Cancer Res 11: 2924-2929, 2005.

17. Mok TS, Wu Y-L, Thongprasert S, et al: Gefitinib or carboplatinpaclitaxel in pulmonary adenocarcinoma. New Eng J Med 361: 947-957, 2009.

18. Mitsudomi T, Morita S, Yatabe Y, et al: Gefitinib versus cisplatin plus docetaxel in patients with non-small-cell lung cancer habouring mutations of the epidermal growth factor receptor (WJTOG3405): an open label, randomized phase 3 trial. Lancet Oncol 11: 121-128, 2010.

19. Maemondo M, Inoue A, Kobayashi K, et al: Gefitinib or chemotherapy for non-small-cell lung cancer with mutated EGFR. New Eng J Med 362: 2380-2388, 2010.

20. Stephens P, Hunter C, Bignell G, et al: Intragenic erbB2 kinase mutations in tumors. Nature 431: 525-526, 2004.
21. Shigematsu H, Takahashi T, Nomura M, et al: Somatic mutations of the HER 2 kinase domain in lung adenocarcinomas. Cancer Res 65: 1642-1646, 2005.

22. Tomizawa K, Suda K, Onozato R, et al: Prognostic and predictive implications of HER2/ERBB2/neu gene mutations in lung cancers. Lung Cancer 74: 139-144, 2011.

23. Sasaki H, Kawano O, Endo K, et al: Uncommon V599E Braf mutations in Japanese patients with lung cancer. J Surg Res 133: 203-206, 2006.

24. Sasaki H, Hikosaka Y, Kawano O, Moriyama S, Yano M and Fujii Y: Evaluation of Kras mutation and copy number gain in non-small cell lung cancer. J Thorac Oncol 6: 15-20, 2011.

25. Ikenoue T, Hikiba Y, Kanai F, et al: Functional analysis of mutations within the kinase activation segment of B-Raf in human colorectal tumors. Cancer Res 63: 8132-8137, 2003.

26. Ji H, Wang Z, Perera SA, et al: Mutations in Braf and Kras converse on activation of the mitogen-activated protein kinase pathway in lung cancer mouse models. Cancer Res 67: 4933-4939, 2007.

27. Welbrock $\mathrm{C}$ and Huristone A: BRAF as therapeutic target in melanoma. Biochem Pharmacol 80: 561-567, 2010

28. Solit DR, Garraway LA, Pratilas CA, et al: BRAF mutation predicts sensitivity to MEK inhibition. Nature 439: 358-362, 2006.

29. Flaherty KT, Puzanov I, Kim KB, et al: Inhibition of mutated activated Braf in metastatic melanoma. N Eng J Med 363: 809-819, 2010.

30. Minami Y, Shimamura T, Shah K, et al: The major lung cancerderived mutants of ERBB2 are oncogenic and are associated with sensitivity to the irreversible EGFR/ERBB2 inhibitor HKI-272. Oncogene 26: 5023-5027, 2007.

31. Greulich H, Chen TH, Feng W, et al: Oncogenic transformation by inhibitor-sensitive and -resistant EGFR mutants. PLoS Med 2: e213, 2005

32. Sasaki H, Endo K, Takada M, et al: EGFR exon20 insertion mutation in Japanese lung cancer. Lung Cancer 58: 324-328, 2007. 